\title{
Documentos cuneiformes inéditos do Museu do Louvre: os arquivos da Família Sanum
}

\author{
Marcelo Rede \\ Universidade Federal Fluminense \\ Brasil
}

Resumo. Uma das tarefas essenciais da epigrafia cuneiforme é tornar disponíveis os milhares documentos que repousam inéditos nas reservas dos museus. No que diz respeito à história econômica, uma etapa incontornável é reagrupar e publicar os arquivos familiares mesopotâmicos, fonte da considerável renovaçäo dos estudos assiriológicos nas últimas décadas. Neste artigo, apresentamos as cópias, traduçöes e comentários filológicos de alguns tabletes inéditos do Museu do Louvre, que completam os arquivos conhecidos da importante família Sanum que viveu em Larsa, durante o período Babilônico Antigo.

Palavras-chave. Larsa; Mesopotâmia; arquivos familiares; Sanum; escrita cuneiforme; Museu do Louvre.

Nos últimos trinta anos, a história econômica da antiga Mesopotâmia passou por uma considerável transformação. Um dos vetores mais importantes da renovação neste campo foi, certamente, o estudo da economia dos grupos domésticos. Operou-se, assim, uma mudança de ênfase cuja importância historiográfica necessita ainda ser devidamente avaliada': enquanto que, por muito tempo, os estudos privilegiaram a esfera palaciana e templária, como decorrência de uma maciça presença de documentos cuneiformes provenientes destes setores (espaço privilegiado da atenção dos arqueólogos), os anos oitenta do século XX viram surgir um grande número de análises sobre a vida material familiar ${ }^{2}$.

' Para uma consideração preliminar, ver M. VAN DE Mieroop (Cuneiform texts and the writing of history. London, Routledge, 1999, p. 106 ss.).

${ }^{2}$ Este marco cronológico não é, evidentemente, rígido e tem apenas a finalidade didática de salientar a mudança de panorama induzida pelos estudos sobre arquivos familiares nos anos oitenta. Os precedentes, no entanto, são freqüentes: já em 1908, J.-E. GAUTIER escrevia sua monografia sobre os arquivos de uma família de Dilbat, na época paleobabilônica (Archives d'une famille de Dilbat au temps de la première dynastie de Babylone, Le Caire, 1908). No caso de Larsa, os primeiros trabalhos decididamente centrados sobre os grupos familiares são os de L. Matouš, Les contrats de partage de Larsa provenant des archives d'Iddin-Amur- 
A condição indispensável para o desenvolvimento desses estudos foi a constituição de arquivos familiares: tratava-se de reunir, a partir dos dados das escavações e das informações prosopográficas, um conjunto coerente de documentos que haviam pertencido a uma família, por vezes atravessando gerações, e que serviria, então, de base para a análise. Assim, um grande esforço foi envidado pelos assiriólogos no sentido de superar uma situação bastante caótica, em que documentos individuais acumulavam-se nos museus e nas publicações, e de estabelecer uma identificação sistemática dos arquivos familiares. Foi deste modo que, para todos os sítios e para todas as épocas, vimos surgirem grandes conjuntos documentais coerentes que poderiam fornecer informações sobre as atividades econômicas de famílias de mercadores, de produtores rurais, de membros das elites urbanas, palaciana e templária, de 'banqueiros' etc.

A publicação dos documentos (contratos, cartas, processos, registros contábeis...) que formam os arquivos familiares é, portanto, uma tarefa essencial da atividade de pesquisa. Neste artigo, damos uma contribuição para completar os arquivos já publicados da família Sanum de Larsa, apresentando a edição de alguns tabletes inéditos do Museu do Louvre, cujo conteúdo já era conhecido, grosso modo, pelas cópias de seus envelopes.

\section{O sítio de Tell Senkereh e sua documentação: um breve histórico}

O sítio de Tell Senkereh, a antiga cidade-reino de Larsa, encontra-se a 270 quilômetros ao sul de Bagdá, na região das planícies meridionais, onde é vizinho de Tell Muqqayar (a antiga cidade de Ur, $43 \mathrm{~km}$ a sudeste) e de Warka (antiga Uruk, apenas $19 \mathrm{~km}$ a oeste). A identificação e as primeiras sondagens arqueológicas modernas em Senkereh foram realizadas em 1854 pelo escocês William Keneth Loftus, que se encontrava na região para uma missão de exploração em Uruk, enviado pelo Assyrian Excavation Fund. Este primeiro olhar sobre Larsa foi descrito três anos mais tarde, em seu Travels and Researches in Chaldaea and Susiana³. Em 1903, o alemão Walter Andrae, escavador de Assur, procedeu igualmente a algumas sondagens

rum, Archiv Orientální, 17, p. 142-175, 1949 e Les contrats de vente d'immeubles provenant de Larsa, Archiv Orientální, 18, p. 11-67, 1950, nos quais, justamente, os membros da família Sanum tiveram lugar de destaque. Na mesma época, em seu trabalho sobre os mercadores de Larsa, W.F. LeEmans ( The Old-Babylonian merchant - his business and his social position, Studia et Documenta ad Iura Orientis Antiqui Pertinentia, 3, Leiden, E.J. Brill, 1950) pôde identificar e analisar várias famílias da cidade. Estes dois autores foram os primeiros a estabelecer, simultânea e paralelamente, a árvore genealógica da família Sanum.

${ }^{3}$ Reeditado em W.K. Loftus, Travels and researches in Chaldaea and Susiana, London, James Nisbet \& Co., 1971 [original: 1857]. 
sobre o tell e fez os primeiros planos do sítio, utilizados mais tarde por André Parrot, o primeiro escavador oficial de Larsa. Estas primeiras investigações permitiram identificar alguns dos maiores edifícios da cidade: o Ebabbar, templo dedicado à divindade principal da cidade, Šamaš, e a ziggurat. Poucos textos foram encontrados nestas duas primeiras explorações do sítio. Em Tell Senkereh, como em outras escavações do início do século XX, predominava o interesse pelos grandes monumentos e pelas estruturas palacianas e religiosas, de modo que os quarteirões de habitação só foram objeto de estudo nas campanhas mais recentes ${ }^{4}$.

Mais tarde, uma permissão de escavação foi concedida pelo governo iraquiano ao Museu do Louvre e os trabalhos tiveram início em 1933, sob a direção de André Parrot, que, ao mesmo tempo, escavava Telloh, a antiga Girsu. Esta missão, no entanto, não teve seqüência: no mesmo ano, a descoberta de Mari (Tell Hariri), situada $600 \mathrm{~km}$ ao norte, atraiu a atenção de Parrot. Os acordos propostos pelo governo da Síria (o sítio de Mari encontrase atualmente a poucos quilômetros da fronteira, em território sírio), mais generosos quanto à partilha dos objetos encontrados coincidiu, justamente, com o momento em que, após a independência face ao domínio inglês, o Iraque instituía leis mais restritivas e passava a controlar suas antiguidades nacionais: assim, os antigos acordos que previam uma divisão dos achados entre os escavadores estrangeiros e o país chegavam ao fim e todas as peças deveriam ser doravante encaminhadas aos museus iraquianos. Para o Louvre, que financiava as missões de Parrot, esta era uma situação bastante desestimulante. Tais fatores foram decisivos para o abandono de Larsa e a transferência para Mari, que se tornou, por décadas, o principal sítio mesopotâmico para a arqueologia francesa. Foi somente em 1967 que as escavações oficiais voltaram a Larsa, novamente sob a direção do incansável Parrot.

A primeira missão de Parrot também dedicou-se prioritariamente às grandes estruturas arquitetônicas do sítio, em particular o palácio de NûrAdad. No entanto, novidade importante, uma quantidade considerável de residências foi reparada e um grande esforço foi consagrado aos quarteirões de habitação da época paleobabilônica, bem como àqueles mais tardios, neobabilônicos e selêucidas. Em seus escritos posteriores, Parrot conferiu uma atenção especial às tumbas situadas sob essas habitações ${ }^{5}$.

${ }^{4}$ Para estas primeiras explorações do sítio, ver L. Bachelot, Larsa: les travaux de la mission archéologique française, 1933-1981, Archiv für Orientforschung, 29/30, p. 167-170, 1983/1984. Para a expedição de Loftus, ver ainda H.V. HiLPrecht, The Babylonian Expedition of the University of Pennsylvania, V. 1, Philadelphia, University of Pennsylvania, 1904.

${ }^{5}$ A. Parrot, Malédictions et violations de tombes, Paris, Geuthner, 1939; para Larsa, ver p. 12. Os relatórios desta primeira expedição jamais foram publicados; ver, em todo caso, o re- 
As escavações de Parrot, em particular das casas, permitiram, desde muito cedo, constatar um fenômeno que foi determinante para o estado da documentação epigráfica de Larsa e que condicionou amplamente os futuros estudos sobre a cidade: o tell havia sido duramente pilhado por escavadores clandestinos. Foram, justamente, estas pilhagens ilegais, largamente retomadas em 1931, que levaram o Departamento de Antiguidades do Iraque a dar a autorização de escavação ao Louvre. O problema era, no entanto, mais antigo, datando do início do século XX: durante suas primeiras décadas, milhares de tabletes de Larsa chegaram aos antiquários de Bagdá, a partir de onde foram dispersos pelo mundo. Foi nesta época que as principais coleções de tabletes de Larsa foram formadas pelos museus europeus e norte-americanos, através de aquisições no mercado de antigüidades.

As pilhagens foram tão extensas que todas as missões francesas desde 1967 acrescentaram muito pouco à documentação epigráfica ${ }^{6}$. Quando as casas do quarteirão residencial nordeste foram escavadas durante as duas

latório preliminar de Parrot, Les fouilles de Tello et de Senkereh-Larsa - Campagne 1932-1933 - Rapport préliminaire. Revue d'Assyriologie et d'Archéologie Orientale, 30, p. 169-182, 1933.

${ }^{6}$ Sobre as descobertas epigráficas, ver D. Arnaud, Catalogue des textes trouvés à Tell Senkereh-Larsa en 1969 et 1970, Syria, 48. p. 289-293, 1971; Larsa, catalogue des textes et d'objets inscrits trouvés au cours de la sixième campagne, Syria, 53. p. 47-81, 1976. Para as duas missões de 1967, ver A. PArrot, Fouilles de Larsa (Senkereh), 1967, Sumer, p. 39-44, 1968. As duas missões seguintes, a $4^{\mathrm{a}}(1969)$ e a $5^{\mathrm{a}}(1970)$ foram conduzidas por J.-Cl. MARGUERON (Larsa, rapport préliminaire sur la quatrième campagne, Syria, 47, p. 262-277, 1970 e Larsa, rapport préliminaire sur la cinquième campagne, Syria, 48, p. 271-278, 1971, respectivamente). A partir de 1974, J.-L. Huot foi o responsável pelo canteiro. Para a $6{ }^{a}$ missão (1974), ver Huot, Derniers travaux à Larsa [Iraq] en 1974 et 1976, Comptes Rendus de l'Académie des Inscriptions, p. 430-439, 1977; para a $7^{\text {a }}$ missão (1976), ver Huot ET AL. Larsa, rapport préliminaire sur la septième campagne à Larsa et la première campagne à Tell el 'Oueili, Syria, 50, p. 183-223,

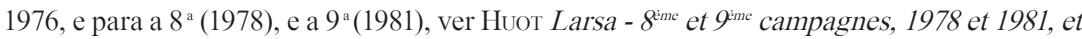
'Oueili, $2^{\text {ime }}$ et $3^{\text {ime }}$ campagnes, 1978 et 1981, Paris, ERC, 1983. Para a $10^{\text {a }}$ missão (1983), ver Нuот, L'Ebabbar de Larsa durant le $1^{\text {er }}$ millenaire (travaux de 1983), Akkadica, 44, p. 14-20, 1985 e Larsa (10 ${ }^{\text {ime }}$ campagne, 1983) et 'Oueili (4'me campagne, 1983), Rapport préliminaire, Paris, 1987. Para a $11^{\text {a }}$ missão (1985), ver Larsa, Travaux de 1985, Paris, 1989; para a 12 a missão (1987), ver Les travaux français à Tell el 'Oueili et Larsa, un bilan provisoire. Akkadica, 73, p. 1-32, 1991. Para a 13 a missão (1989), ver Huot, Tell es-Sinkarah - Larsa (Iraq), Orient Express, 1, p. 3, 1991; Y. Calvet, 'Maisons privées paléo-babyloniennes à Larsa - Remarques d'architecture', in K.R. VeENHOF, ed., Houses and households in ancient Mesopotamia, 40 Rencontre Assyriologique Internationale, Leiden, Nederlands Historisch-Archaeologisch Intstituut te Istanbul, 1993, p. 197-209, e 'Les grandes résidences paléo-Babyloniennes de Larsa', in H. Gasche et Al., eds., Cinquante-deux réflexions sur le Proche-Orient ancien, Mélanges Léon De Meyer / Mesopotamian History and Environment, Occasional Publlications, 2, Leuven, Peeters, 1994, p. 215-228; Y. Calvet, J.-P. Thalman \& J.-L. Huot, Tell es-Sinkara/Larsa, 1987 and 1989, Archiv für Orientforschung, 38/9, p. 276-279, 1991/2 e, sobretudo, o relatório final das missões de 1987 e 1989: Нuot, Larsa, Travaux de 1987 et 1989, Bibliothèque Archéologique et Historique, 165, Beiruth, Institut Français d'Archéologie du Proche-Orient, 2003. 
últimas missões, em 1987 e 1989, foram encontrados apenas edifícios esvaziados de seus arquivos, contendo poucos tabletes isolados?

A maior parte dos textos de Larsa conhecidos atualmente é, portanto, originária de escavações clandestinas do início do século XX, sendo, assim, completamente desprovida de contexto arqueológico. Por vezes, os arquivos encontrados em uma residência foram desmembrados para venda e encontram-se, hoje, em museus diferentes. Assim, o reagrupamento dos arquivos familiares depende prioritariamente de análises prosopográficas do conteúdo dos textos.

Quanto à sua tipologia, os textos de Larsa são bastante diversificados, mas dois grupos predominantes devem ser mencionados:

a) Cartas. Um primeiro grupo é constituído por cartas reais e entre os funcionários da administração palaciana. Muitas delas datam da época de independência do reino de Larsa (ver abaixo). No entanto, o lote mais importante vem da época da dominação babilônica da cidade. A distância entre as duas cidades, cerca de 200 km, implicava uma constante comunicação por escrito entre a administração central e seus representantes locais. Muitas das vezes, era o próprio rei que se dirigia a seus servidores. É assim que Larsa nos forneceu a quase totalidade do que conhecemos da prestigiosa correspondência de Hammu-rabi ${ }^{8}$. O fato é ainda mais relevante porque a movimentação do lençol freático sob o sítio de Babilônia impediu, até aqui, toda exploração sistemática dos estratos de época paleobabilônica; assim, nada dos arquivos palacianos da capital é conhecido, a não ser o que foi encontrado na periferia, como as cartas enviadas a Larsa ou Mari?. Um segundo grupo, é formado por cartas privadas. No entanto, como estas, ao contrário dos contratos, não trazem fórmula de datação ou dados cadastrais, é bastante difícil identificar sua origem apenas a partir dos nomes presentes, sobretudo quando se trata de tabletes escavados clandestinamente, como é o caso de Larsa ${ }^{10}$.

${ }^{7}$ Sobre estas raras descobertas epigráficas, ver a contribuição de D. Charpin, La politique immobilière des marchands de Larsa à la lumière des découvertes épigraphiques de 1987 et 1989, in J.-L. Huot (ed.), Larsa - Travaux de 1987 et 1989, Bibliothèque Archéologique et Historique, 165, Beyrouth, Institut Français d'Archéologie du Proche-Orient, p. 311-322, 2003, p. 313ss.

${ }^{8}$ Para uma tradução feita diretamente a partir das cópias cuneiformes, ver E. Bouzon, As cartas de Hammurabi, Petrópolis, Vozes, 1986.

${ }^{9}$ Para as informações sobre Babilônia (e Larsa) encontradas nas cartas de Mari, ver D. Charpin, 'Les représentants de Mari à Babylone', in D. Charpin et Al., Archives Epistolaires de Mari I/2, Archives Royales de Mari, 26/2, Paris, ERC, 1988, p. 147 e 187 e M. Birot, Correspondance des gouverneurs de Qattunân, Archives Royales de Mari, 27, Paris, ERC, 1993, p. 34 ss. 
b) Contratos. Trata-se da documentação por excelência encontrada nas residências, formando o grosso dos arquivos familiares. Constitui-se de registros de compra de imóveis, empréstimos, partilhas de herança, dotes, casamentos, documentos comerciais de toda sorte etc.

Como os tabletes publicados aqui pertencem a esta última categoria, será útil uma descrição mais detalhada do estado desta documentação. Nas coleções modernas, três grandes conjuntos de contratos de Larsa da época babilônica antiga foram formados:

a) A Yale Babylonian Collection possui o lote mais importante. Mais de 300 cópias cuneiformes foram publicadas nos volumes 5 (de 1919) e 8 (de 1941) da Yale Oriental Series (YOS), por E. M. Grice e D. E. Faust, respectivamente ${ }^{11}$. No entanto, uma quantidade considerável de contratos de Yale aguarda ainda uma publicação ${ }^{12}$.

b) Os tabletes da coleção de Berlin foram editados em 1914, no volume 13 de Voderasiatische Schriftdenkmäler der staatlichen Museen zu Berlin (VS), em cópias de H.H. Figulla ${ }^{13}$.

c) Os 250 contratos do Museu do Louvre foram copiados por Ch.-F. Jean na série Textes Cunéiformes du Louvre (TCL) e publicados em 1926. Com algumas poucas exceções, a primeira série (volume TCL,10) reúne os documentos da época da dinastia de Larsa e a segunda série (volume TCL,11), aqueles posteriores à conquista da cidade pelo rei babilônico Hammu-rabi ${ }^{14}$.

${ }^{10}$ As cartas da época babilônica antiga, reais ou privadas, vêm sendo sistematicamente editadas, em transcrição e tradução, na série Altbabylonische Briefe (AbB), com 14 volumes publicados até o momento.

"Para YOS, 5, ver E.M. GRICE, Records from Ur and Larsa dated in the Larsa Dynasty, Yale Oriental Series, 5, New Haven, Yale University Press, 1919. Para YOS, 8, ver D. E. FausT, Contracts from Larsa dated in the reign of Rîm-Sinn, Yale Oriental Series, 8, New Haven, Yale University Press, 1941. Alguns documentos de YOS, 8 já haviam sido publicados por E. Grant, Babylonian Business Documents of the Classical Period, Philadelphia, 1919.

${ }^{12}$ Por enquanto, ver os catálogos dos textos de Yale publicados por G. BECKMan, Old Babylonian archival texts in the Nies Babylonian collection, Catalogue of the Babylonian Collections at Yale, 2, Bethesda, CDL Press, 1995; Old Babylonian archival texts in the Yale Babylonian collection, Catalogue of the Babylonian Collections at Yale, 4, Bethesda, CDL Press, 2000.

${ }^{13}$ H.H. Figulla, Altbabylonische Verträge, Vorderasiatische Schriftdenkmäler der staatlischen Museen zu Berlin, 13, Leipzig, J.C. Hinrichs'sche Buchhandlung, 1914. Os textos larseanos de Berlin foram incluídos nos importantes volumes das Hammurabi’s Gesetz de J. Kohler e A. Ungnad, fornecendo o material contratual complementar para o estudo das leis babilônicas, em particular do código de Hammu-rabi.

${ }^{14}$ Ver Ch.-F. JeAn, Contrats de Larsa. Première série (Textes Cunéiformes du Louvre, 10), Paris, Geuthner, 1926; Contrats de Larsa. Seconde série (Textes Cunéiformes du Louvre, 11), Paris, Geuthner, 1926. 
À parte estes três grandes conjuntos, deve-se registrar a existência de vários contratos de Larsa dispersos em coleções menores, mas também importantes. Os 68 tabletes da coleção Liagre Böhl, de Leiden, foram copiados por W. F. Leemans no primeiro volume da série Tabulae Cuneiformes a F.M. Th. de Liagre Böhl Collectae (TLB) ${ }^{15}$. Entre os 146 tabletes paleobabilônicos conservados no Museu de Leningrado (hoje, novamente São Petesburgo), vários são provenientes de Senkereh; o conjunto foi publicado por A. P. Riftin em Starovavilonskie Juridiceskie i Administrativnie Dokumenti v Sobranijach SSSR, em $1937^{16}$. Mais recentemente, H. Limet publicou 14 tabletes da Universidade de Liège que faziam parte dos arquivos de um só comprador de terrenos de Larsa ${ }^{17}$. Alguns outros contratos encontram-se dispersos pelo mundo ${ }^{18}$.

Paradoxalmente, o percurso destes textos, desde as escavações clandestinas até sua entrada nos museus, não foi completamente aleatório e, de modo freqüentemente involuntário, alguns lotes coerentes foram preservados no processo de negociação no mercado de antigüidades. Assim, nota-se que todos os documentos pertencentes à família Sanum acabaram por integrar a coleção do Museu do Louvre. Do mesmo modo, houve, por exemplo, um reagrupamento quase completo dos arquivos do importante personagem Balmunamhe no Museu da Universidade de Yale ${ }^{19}$; os contratos de UbarŠamaš concentram-se em Berlin, enquanto que os arquivos de Amurrumšemi encontram-se em Liège e os de Warad-Zugal e Balâlum, em Leiden. Nós podemos supor que os documentos encontrados pelos escavadores clandestinos em uma residência antiga eram vendidos em lote a um mercador de antigüidades de Bagdá, que, por sua vez, tendia a repassá-los, também em bloco, aos compradores dos museus.

${ }^{15}$ W.F. LeEmans, Old Babylonian legal and administrative documents (Tabulae Cuneiformes a F. M. Th. De Liagre Böhl Collectae, Leidae conservatae, 1), Leiden, Nederlandsch Instituut voor het Nabije Oosten, 1954. O próprio Leemans apresentou uma primeira transcrição e tradução destes documentos em Legal and economic records from the Kingdom of Larsa (Studia ad Tabulas Cuneiformas Collectas a F. M. Th. De Liagre Böhl Pertinentia, 1/2), Leiden, E.J. Brill, 1954.

${ }^{16}$ A.P. Riftin, Starovavilonskie Juridiceskie i Administrativnie Dokumenti v Sobranijach SSSR, Moskau/Leningrad, 1937.

${ }^{17}$ H. Limet, Amurru-šemi, propriétaire foncier à Larsa, Akkadica, Suppl. 6, Mélanges André Finet, p. 99-111, 1989.

${ }^{18}$ Existem textos isolados no Ashmolean Museum, no Horn Archaeology Museum da Universidade de Andrews, na École Pratique des Hautes Études, em Paris, e na Totten Collection.

${ }^{19}$ Sobre Balmunamhe e suas atividades econômicas, ver M. VAn de Mieroop, The archive of Balmunamhe, Archiv für Orientforschung, 34, p. 1-29, 1987; M. PERs, La famiglia di Balmunamhe di Larsa, Pisa, Tese di Laurea, Università di Pisa, 1996, e La famiglia di Balmunamhe di Larsa, Egitto e Vicino Oriente, 20/21, p. 139-148, 1997/8. 
A concentração dos contratos nos arquivos de algumas poucas famílias facilitou a tarefa de atribuição dos tabletes ao sítio de Larsa. A princípio, apenas os mercadores de antigüidades garantiam as informações sobre sua proveniência. As primeiras leituras, no entanto, mostraram que uma grande parte dos contratos pertenceu a certos indivíduos e famílias e, uma vez que os dados confirmaram a ligação destes com Larsa, a origem de arquivos inteiros pôde ser atribuída com segurança ao sítio de Senkereh ${ }^{20}$.

Dentre os grupos familiares que aparecem representados nos contratos, o formado pelos descendentes de Sanum é um dos mais importantes, quer por sua representatividade documental, que por seu alcance econômico. Os arquivos cobrem um período de mais de 90 anos: os primeiros documentos são datados dos anos 2 e 3 do rei Sîn-iqî̌sam (pouco depois de 1840 a.C.), de Larsa, e os últimos datam do ano 7 de Samsu-iluna, da Babilônia (1743). A atividade do grupo atravessou, portanto, os dois períodos da história política da cidade durante o período babilônico antigo: a fase de independência, em que os dois principais soberanos foram Warad-Sîn (1835-1823) e seu irmão RîmSîn (1822-1763), e a fase de domínio babilônico, inaugurada por Hammu-rabi (1792-1750), que conquistou a cidade em seu $31^{\circ}$ ano de reinado, e continuada por seu filho Samsu-iluna (1749-1712), que termina por perder o controle da cidade e, com ela, do sul mesopotâmico por volta de seu $11^{\circ}$ ano de reinado, aparentemente no bojo de uma insurreição geral contra o domínio babilônico.

Os arquivos da família Sanum contam, hoje, com 63 documentos diretos, isto é, que tratam de negócios em que membros da família estiveram pessoalmente implicados. Isto corresponde a nada menos de $25 \%$ dos contratos alojados no Louvre. A estes, podemos acrescentar outros dois contratos cujos dados cadastrais permitem vinculá-los aos negócios imobiliários da família e que, provavelmente, fizeram parte de seus arquivos, como documentos comprobatórios das transações. Um deles, TCL,10,15, que era conhecido apenas pela cópia do envelope, tem o seu tablete apresentado neste artigo. Estes documentos — que não são produto de operações envolvendo diretamente membros da família, mas que, devido a estes negócios, devem ter terminado em seus arquivos - compõem o que poderíamos chamar de 'arquivo periférico ${ }^{211}$.

${ }^{20}$ Assim, por exemplo, desde 1914, H.H. Figula havia reparado os arquivos de UbarŠamaš (Altbabylonische Verträge. Vorderasiatische Schriftdenkmäler der staatlischen Museen zu Berlin, vol. 13. Leipzig, J.C. Hinrichs'sche Buchhandlung, 1914. p. iii) e, em 1916, E. GRAnT notou a existência de um lote de tabletes que formavam uma parte dos arquivos de Balmunamhe (Balmunamğe, the slave dealer, The American Journal of Semitic Languages, 34, p. 199-204, 1917/8), amplamente enriquecidos, alguns anos mais tarde, com a publicação dos contratos de Yale.

${ }^{21}$ Hoje, conhecemos razoavelmente os mecanismos que levavam à formação dos arquivos familiares (ver C. Saporetti, Assur 14446: La famiglia A. Acesa e declino di persone 


\section{Os contratos de Larsa no Museu do Louvre}

Dentre os 250 contratos de Larsa que compõem a coleção do Museu do Louvre, 46 são compostos de tablete mais envelope. Esta era uma prática comum nos procedimentos escribais do período, em particular para os contratos ditos privados: uma primeira cópia era feita sobre um tablete de argila; posteriormente o mesmo texto era recopiado pelo escriba sobre um envelope, igualmente de argila, que servia de invólucro protetor do tablete interno. Assim, a princípio, não era necessário abrir o envelope para conhecer o conteúdo do contrato, sobretudo, em caso de contencioso. Tomava-se, além disso, o cuidado de colocar tablete e envelope em posições invertidas; deste modo, em caso de dano de uma das extremidades, o conjunto do texto poderia ser recuperado a partir das partes remanescentes de tablete $\mathrm{e}$ envelope. Nem sempre o texto do envelope correspondia exatamente ao do tablete; havendo mais superfície naquele, o escriba podia acrescentar dados omitidos neste último: o nome de uma ou mais testemunhas; a filiaçäo ou a profissão das pessoas envolvidas; dados mais detalhados sobre a localização de um terreno negociado etc. Por vezes, há diferenças mais consideráveis entre os dois textos e mesmo divergências explícitas (eventualmente, devidas a erro do escriba), como, por exemplo, a diferença de preço. Do ponto de vista museográfico e da edição de textos, isto significa que, em geral, o envelope é mais completo do que o tablete, mas, por ser mais exposto, encontra-se normalmente mais deteriorado, dificultando a cópia e a leitura. Já o tablete, beneficiado pela proteção do envelope durante milênios, é mais

e famiglie all'inizio del medio-regno assirio, V. 1, Malibu, Undena Publications, 1979, p. 8 e, sobretudo, D. Charpin, Transmission des titres de propriété et constitution des archives privées en Babylonie ancienne, in K.R. Veenhof, ed., Cuneiform archives and libraries, $30^{\mathrm{e}}$ Rencontre Assyriologique Internationale, Leiden, Nederlands Historisch-Archaeologisch Instituut te Istanbul, 1986, p. 121-140. No caso das transações imobiliárias, além do contrato comprovando a aquisição, o comprador recebia também os documentos anteriores, que provavam a trajetória do terreno, como as atas de partilha e de vendas precedentes; são estes últimos que chamo de arquivos periféricos. No caso de créditos a receber não pagos ou anulados por edito real, o credor acumulava em seus arquivos uma grande quantidade de contratos de empréstimo tornados sem efeito (cf. D. Charpin, Les prêteurs et le palais: les édits de mî̌sarum des rois de Babylone et leurs traces dans les archives privées, in A.C.V.V. Bongennar, ed., Interdependency of institutions and private entrepreneurs, MOS Studies, 2, Leiden, Historisch-Archaeologisch Instituut te Istanbul, 2000, p. 185-211). Estudando o arquivo comercial de Ibni-Amurrum, membro da família Sanum, eu pude demonstrar que o inverso também ocorria: um bom pagador acumulava em seus arquivos os contratos dos empréstimos que fizera, como comprovantes da quitação de seus débitos (cf. M. REDE, 'Le commerce sans marché à l'époque de Hammu-rabi - Réevaluation d'une thèse polanyienne à partir d'une étude de cas', in Clancier, Ph. et al., eds., Autour de Polanyi - Vocabulaires, théories et modalités des échanges, Paris, De Boccard, 2005, p. 135-154). 
preservado e pode fornecer informações perdidas no texto do invólucro. O ideal é, pois, publicar a cópia cuneiforme de ambas as peças. No entanto, a abertura do envelope de argila, é uma operação delicada e, no mais das vezes, danifica irremediavelmente o texto e as impressões dos selos da superfície, não importando se o método de abertura seja serrar o envelope (operação que arrisca atingir o tablete ${ }^{22}$ ) ou, simplesmente, quebrá-lo em pedaços (se, a princípio, a visão dos cacos pode parecer um tanto bárbara, a restauração permite recuperar grande parte da peça original). No acervo do Louvre, ambos os métodos foram usados alternativamente, com resultados variáveis. No mais, os museus têm opiniões e políticas diferentes quanto a esta questão e a abertura dos tabletes nem é sempre permitida. Dos 46 contratos de Larsa duplicados (tablete + envelope), 23 já estavam abertos (ou o foram na ocasião) quando Charles-François Jean publicou suas cópias cuneiformes nos volumes 10 e 11 da série Textes Cunéiformes du Louvre. Nestes casos, o epigrafista copiou os dois textos. O quadro abaixo mostra a lista completa:

Quadro 1. Tabletes duplos publicados em TCL

\begin{tabular}{|c|c|c|}
\hline $\mathrm{N}^{\circ}$ & AO & TCL \\
\hline 1 & 6350 & 10,7 \\
2 & 6351 & 10,8 \\
3 & 6353 & 10,10 \\
4 & 6358 & 10,46 \\
5 & 6359 & 10,50 \\
6 & 6363 & 10,23 \\
7 & 6364 & 10,35 \\
8 & 6374 & 10,41 \\
9 & 6375 & 10,36 \\
10 & 6376 & 10,14 \\
11 & 6380 & 10,4 \\
12 & 6383 & 10,128 \\
13 & 6394 & 10,40 \\
14 & 6402 & 10,70 \\
15 & 6427 & 11,193 \\
16 & 6428 & 10,18 \\
17 & 7045 & 10,59 \\
18 & 8378 & 11,152 \\
19 & 8379 & 11,162 \\
20 & 8380 & 11,167 \\
21 & 8381 & 11,183 \\
22 & 8476 & 10,98 \\
23 & 8477 & 10,117 \\
\hline
\end{tabular}

${ }^{22}$ É, justamente, o que ocorreu com alguns tabletes do Louvre, como mostram as cópias 
Mais tarde, vários envelopes foram abertos por M. Nougayrol, então conservador-chefe no Louvre, a pedido de W.F. Leemans, estudioso holandês cujos numerosos e importantes trabalhos de história econômica babilônica basearam-se, em grande parte, na documentação de Larsa. Esse autor copiou e publicou 9 destes 'novos' tabletes que diziam respeito ao comércio em seu Foreign Trade in the Old Babylonian Period ${ }^{23}$ :

QuADRo 2. Tabletes publicados por Leemans.

\begin{tabular}{|c|c|c|l|}
\hline $\mathrm{N}^{\circ}$ & AO & TCL & Publicação \\
\hline 1 & 8462 & 10,93 & Leemans, 1960: 64 \\
2 & 8478 & 10,68 & Leemans, 1960: 155 \\
3 & 8479 & 10,56 & Leemans, 1960: 147 \\
4 & 8480 & 10,125 & Leemans, 1960: 59' \\
5 & 8481 & 10,54 & Leemans, 1960: 167 \\
6 & 8484 & 10,20 & Leemans, 1960: 62 \\
7 & 8495 & 11,222 & Leemans, 1960: 66 \\
8 & 8504 & 10,95 & Leemans, 1960: 66 \\
9 & 8527 & 10,82 & Leemans, 1960: 153 \\
\hline
\end{tabular}

${ }^{1}$ Neste caso, Leemans recopiou também o envelope.

Restaram, então, alguns tabletes, agora liberados de seus envelopes, que nunca foram copiados e publicados, assim como alguns fragmentos de envelopes que tinham sido negligenciados por Ch.F. Jean e que eu pude identificar nas gavetas do Museu. Um projeto de publicação do conjunto destes tabletes 'inéditos' está em curso. Eu me limito a fornecer, aqui, a edição dos documentos referentes à família Sanum. Até onde se pode saber, isto completa o arquivo conhecido da família, ressalvada a possibilidade de existência de tabletes não repertoriados alojados em outros museus, como é o caso da coleção já mencionada de Yale. Uma tradução é fornecida para cada documento, com exceção dos textos muito fragmentados. Quando julguei relevante, acrescentei, nos comentários, as diferenças entre os textos aqui apresentados e as cópias feitas por Jean. Do mesmo modo, chamei a atenção para os casos em que as novas cópias permitem uma leitura alternativa ou acréscimos em relação às traduções da edição de E. Bouzon ${ }^{24}$. Em geral, os

aqui publicadas: os longos traços verticais indicam os lugares, normalmente as laterais, em que a serra ultrapassou a espessura da argila do envelope e atingiu o tablete, danificando-o.

${ }^{23}$ W.F. LeEmans, Foreign trade in old Babylonian period as revealed by texts from southern Mesopotamia. Studia et Documenta ad Iura Orientis Antiqui Pertinentia, 6, Leiden, E.J. Brill, 1960.

${ }^{24}$ E. Bouzon, Contratos Pré-Hammurabianos do reino de Larsa, Porto Alegre, Edi- 
novos tabletes permitem pequenos ganhos, como um preço que havia sido perdido, uma data, o nome de uma testemunha ou, ainda, a leitura mais correta de um sinal; são, no entanto, dados importantes, sobretudo para uma análise prosopográfica ou para uma história serial. A lista abaixo (Quadro 3) fornece a equivalência entre os tabletes e fragmentos aqui publicados e as cópias da série TCL:

QuAdro 3. Tabletes inéditos.

\begin{tabular}{|c|c|c|l|}
\hline AO & TCL & Figura & Observações \\
\hline 6354 & 10,6 & 1 & tablete inédito \\
6357 & 10,15 & 2 & tablete inédito (arquivo periférico) \\
6369 & 10,29 & 3 & tablete inédito \\
6389 & 10,37 & 4 & tablete inédito \\
6360 & 10,67 & 5 & tablete inédito \\
6426 & 11,194 & 6 & fragmentos do envelope não copiados por Jean \\
6423 & 11,195 & 7 & lateral superior do tablete visível através de uma \\
6396 & 11,197 & 8 & brecha do envelope \\
6397 & 11,199 & 9 & lateral inferior não copiada por Jean \\
\hline
\end{tabular}

pucrs, 2000. Neste trabalho, limitei-me um tratamento epigráfico e filológico das fontes; para um estudo propriamente historiográfico, eu me permito remeter ao meu estudo sobre a família Sanum: M. Rede, L'Appropriation de l'espace domestique à Larsa - La trajectoire de la famille Sanum, 2 V., Université de Paris I-Panthéon-Sorbonne, Tese de doutorado, 2004. Outrossim, desconsiderei, aqui, as impressões de selos na superfície dos tabletes, que serão objeto de um estudo em separado. 
Cópias, transcrições, traduções e comentários AO 6354 (TCL,10,6 - Tablete)

FIG. 1A

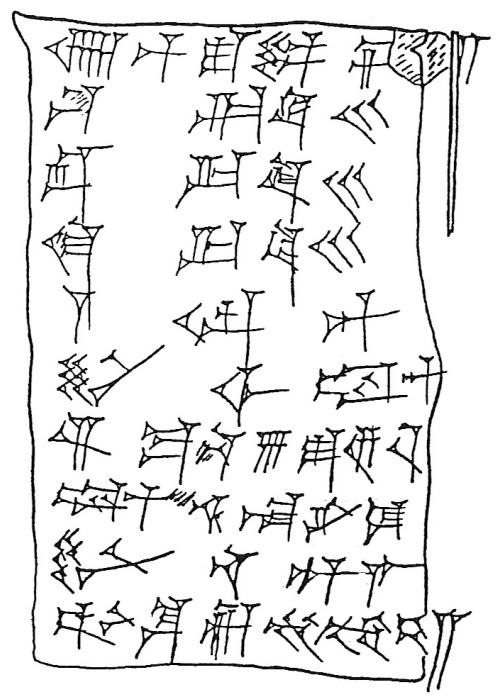

FIG. 1B

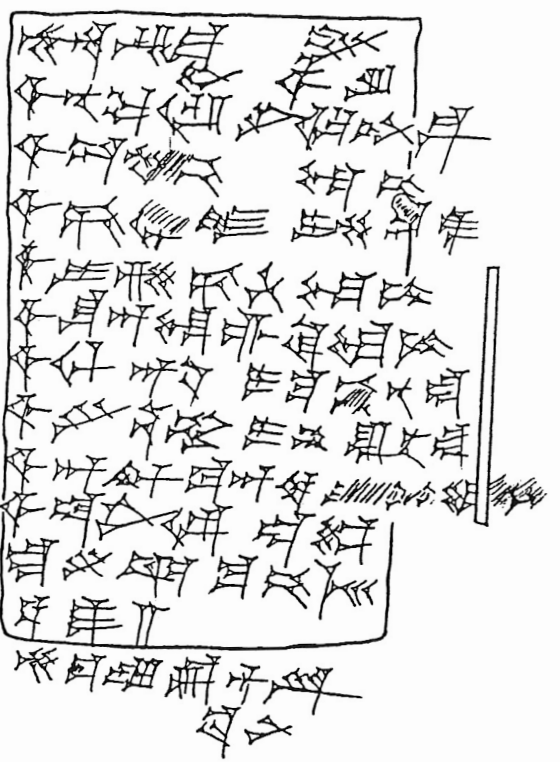




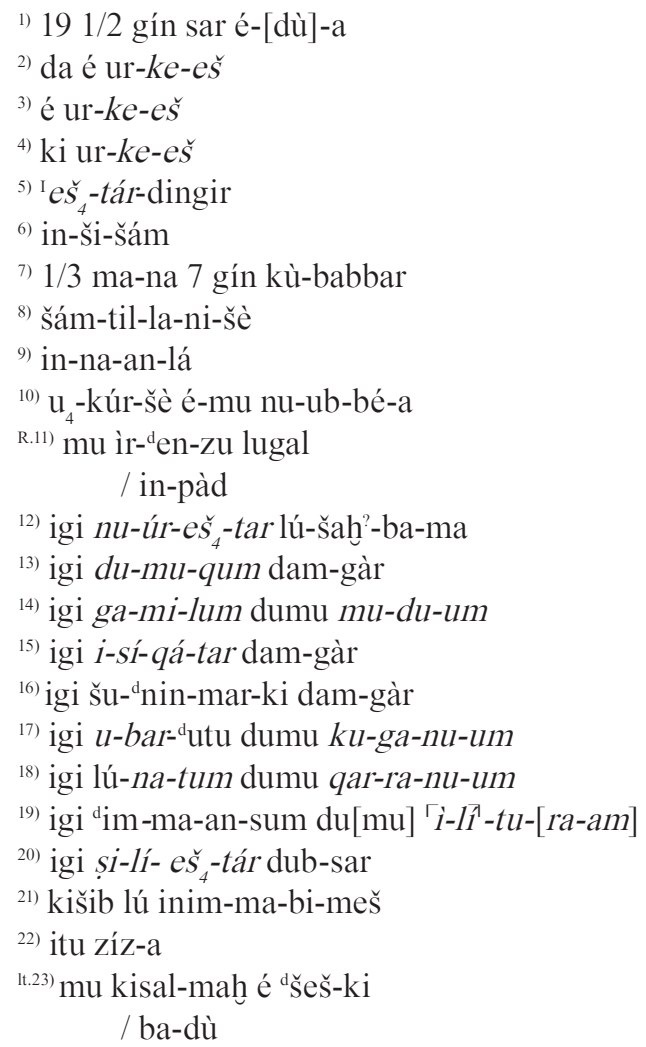

1) 19 1/2 gín sar de terreno construído, ${ }^{2)}$ ao lado do terreno de Ur-Keš, ${ }^{3)}$ terreno (pertencente a) Ur-Keš. ${ }^{5)}$ Eštar-ilî ${ }^{6}$ comprou-o ${ }^{4)}$ de Ur-Keš. ${ }^{8)}$ Por seu preço completo, ${ }^{9)}$ ele pagou ${ }^{7} 1 / 3$ de mina e 7 siclos de prata. ${ }^{10)}$ No futuro, ele não dirá: 'este é meu terreno'. ${ }^{\text {R.11) }}$ Em nome de Warad-Sîn, seu rei, ele jurou. ${ }^{12)}$ Diante de Nûr-Eštar $(\ldots){ }^{13)}$ diante de Dumuqum, mercador, ${ }^{14)}$ diante de Gâmilum, filho de Mudum, ${ }^{15)}$ diante de Ișiqatar, mercador, ${ }^{16)}$ diante de Šu-Ninmarki, mercador, 17) diante de Ubar-Šamaš, filho de Kugânum, ${ }^{18)}$ diante de Awil-natum, filho de Qarranum, ${ }^{19)}$ diante de Adad-mansum, filho de Ilî-turam, ${ }^{20)}$ diante de Șilli-Eštar, escriba. ${ }^{21)}$ Os selos das testemunhas. ${ }^{22)}$ Mês: XI ${ }^{1.23)}$ Ano: 9 de Warad-Sîn.

Dimensões: $7 \times 4,3 \mathrm{~cm}$.

1.7: o preço registrado no tablete ( $1 / 3$ de mina e 7 siclos) é diferente do registrado no envelope ( $1 / 3$ de mina e 7 1/3 siclos).

1.19: o selo de Ilî-turam aparece impresso no contrato; certamente, ele foi usado por seu filho, Adad-mansum, que figura na lista de testemunhas; o mesmo ocorre em outro documento: TCL,10,8. 
AO 6657 (TCL,10,15 — Tablete)

FIG. 2A

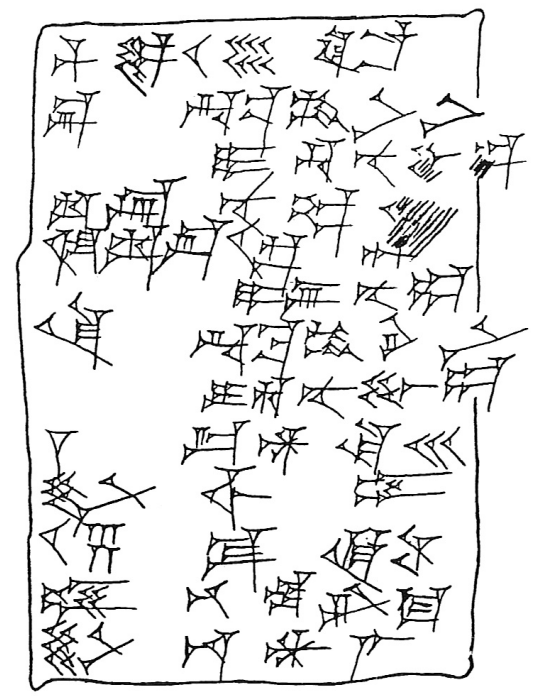

FIG. 2B

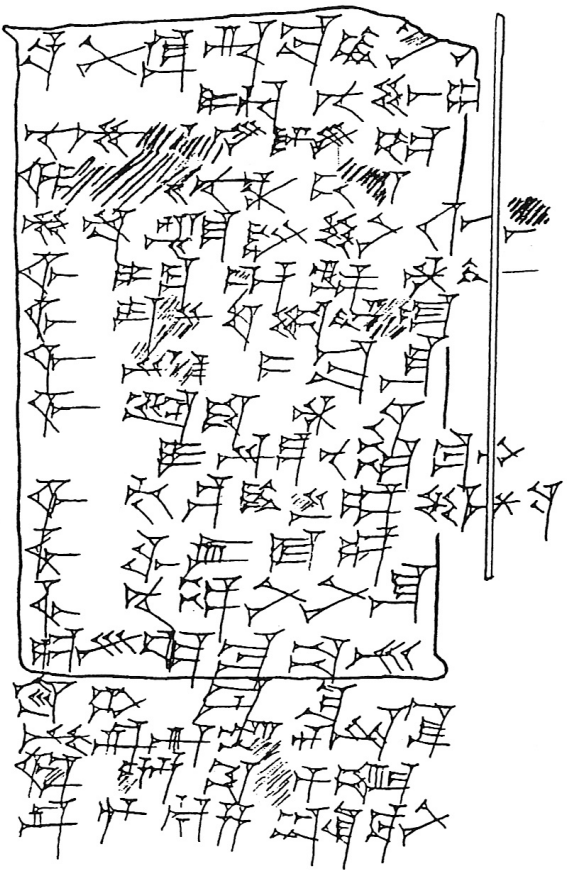




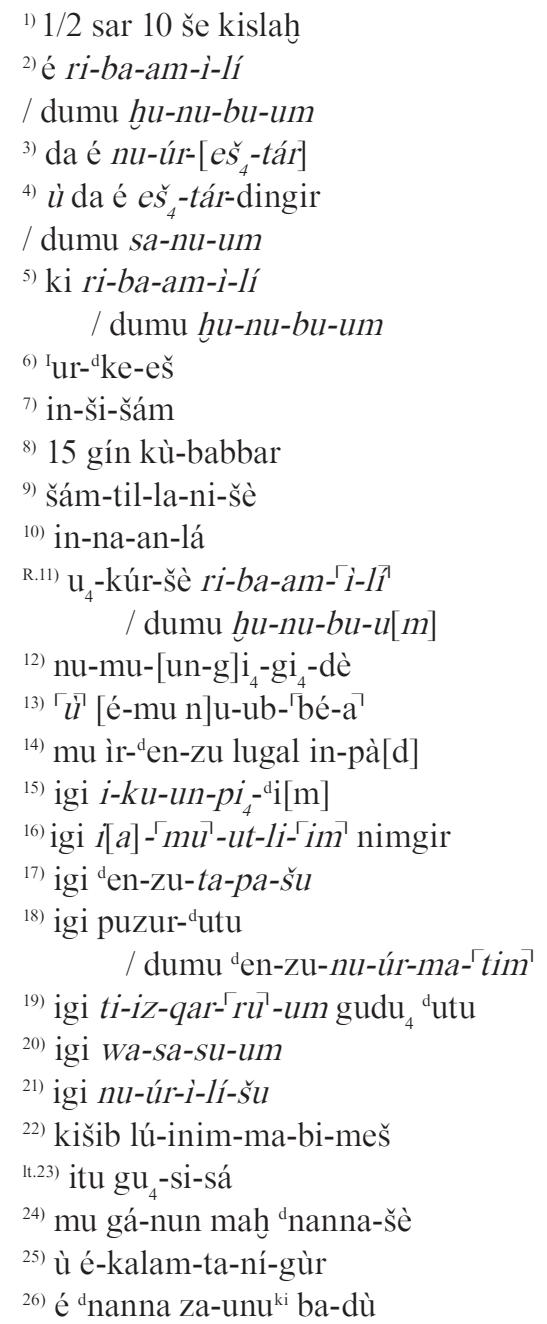

1) $1 / 2$ sar e 10 še de terreno vazio, ${ }^{2}$ terreno (pertencente a) Ribam-ilî, filho de Hunubum, ${ }^{3)}$ ao lado do terreno de Nûr-Eštar ${ }^{4)}$ e ao lado do terreno de Eštarilî, filho de Sanum. ${ }^{6}$ Ur-Keš ${ }^{7)}$ comprou-o ${ }^{5)}$ de Ribam-ilî, filho de Hunubum. 9) Por seu preço completo, ${ }^{10)}$ ele pagará ${ }^{8)} 15$ siclos de prata. ${ }^{\text {R.11) }}$ No futuro, Ribam-ilî, filho de Hunubum ${ }^{12)}$ não se voltará (contra o contrato) ${ }^{13}$ e ele não dirá 'este é meu terreno'. ${ }^{14)}$ Em nome de Warad-Sîn, o rei, ele jurou. ${ }^{15)}$ Diante de Ikun-pî-Adad,${ }^{16)}$ diante de Iamut-Lim, o arauto, ${ }^{17)}$ diante de Sîn-tapašu, ${ }^{18)}$ diante de Puzur-Šamaš, filho de Sîn-nûr-matim, ${ }^{19)}$ diante de Tizqarum, sacerdotepašî̌šum de Šamaš, ${ }^{20)}$ diante de Wasasum, ${ }^{21)}$ diante de Nûr-ilišu, ${ }^{22)}$ Os selos das testemunhas. ${ }^{\text {tr.23) }}$ Mês: II ${ }^{24-26)}$ Ano: 6 de Warad-Sîn. 
Dimensões: $6,5 \times 4,2 \mathrm{~cm}$.

1. 2: O vendedor, cujo nome é aqui grafado Ribam-ilî, é certamente o mesmo Iribam-ilî que, mais tarde, venderá um terreno a Eštar-ilî (TCL,10,8 do mês I do ano 6 de Warad-Sîn), pois, em ambos os casos, eles aparecem como sendo 'filho de Hunubum'. É possível que se trate de um erro do escriba ou que tenha havido duas maneiras de escrever o nome. Ver, igualmente: TCL,10,129:6 e 18 e TCL, 10,130:24.

AO 6369 (TCL,10,29 - Tablete)

FIG. 3A

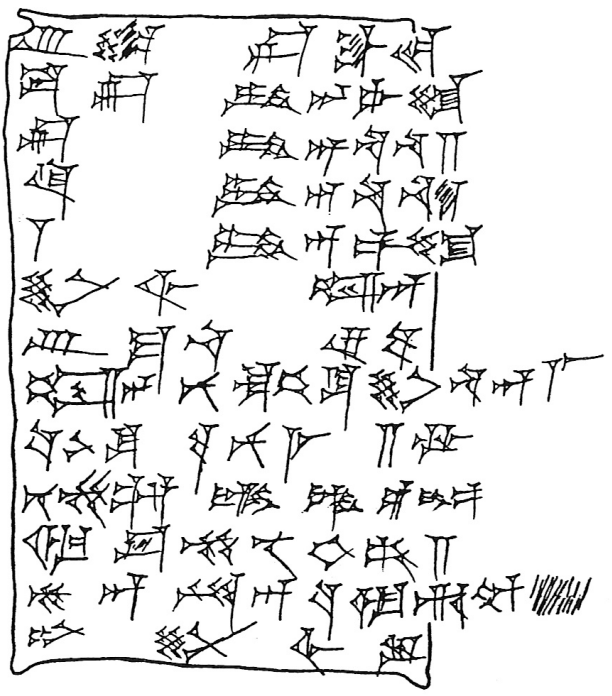


FIG. 3B

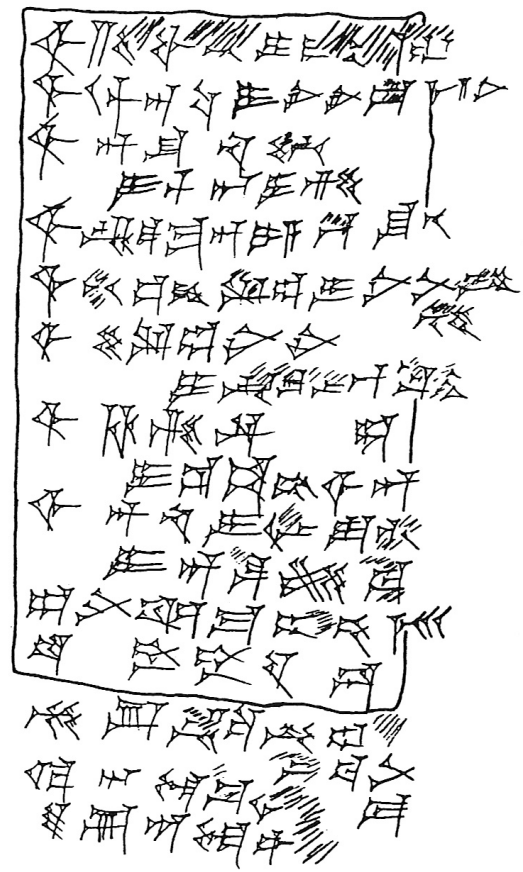

1) $2 / 3$ sar é- ${ }_{\text {gallam }}$

${ }^{2)}$ da é $i$-din- ${ }^{\mathrm{d}}$ mar-tu

3) é $i$-din- ${ }^{d} n a-n a-a$

4) ki $i-d i n-{ }^{d} n a-n a-{ }^{a}$

5) ${ }^{\mathrm{I}} i$-din- ${ }^{\mathrm{d}} \mathrm{mar}-\mathrm{tu}$

6) in-ši-šám

7) $2 / 3$ ma-na kù-babbar

8) šám-til-la-bi-šè in-na-an-lá

${ }^{9)} \mathrm{u}_{4}$-kúr-šè $\mathrm{u}_{4}$-nu-me-a-ak

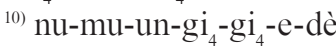

11) ù é-mu nu-ub-bé-a

${ }^{12)}$ mu d nanna ${ }^{\mathrm{d}} \mathrm{utu}$ ù ri-im- $\left[{ }^{\mathrm{d} e n-z u}\right]$

13) lugal in-pàd

R.14) igi a-bu-wa-qar dumu $i-[d]$ in- $[i] r-r a$

${ }^{15)}$ igi $u$-bar- ${ }^{\mathrm{d}}$ utu dumu $i-l i ́-i \check{S}-m e-a-n i$

16) igi 'šu-na-șir

/ dumu d'̌u-dumu-zi

17) igi den-zu-ma-dingir dumu a-hul-šu-nu

18) igi ti-iz-qá-ru-um dumu i-lí-i-dí-

/-nam 


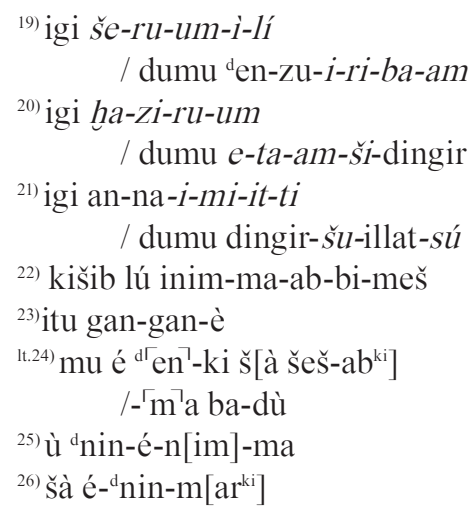

1) $2 / 3$ sar de um cômodo principal, ${ }^{2)}$ ao lado do terreno de Iddin-Amurrum, ${ }^{3)}$ terreno (pertencente a) Iddin-Nanaya. ${ }^{5)}$ Iddin-Amurrum ${ }^{6}$ comprou-o ${ }^{4)}$ de Iddin-Nanaya. ${ }^{8)}$ Por seu preço completo, ele pagou ${ }^{7)} 2 / 3$ de mina de prata. ${ }^{9)}$ No futuro e para sempre, ${ }^{10)}$ ele não se voltará (contra o contrato) ${ }^{11)}$ e ele não dirá: 'este é meu terreno'. ${ }^{12)}$ Em nome dos deuses Nanna et Šamaš e de RîmSîn, ${ }^{13)}$ o rei, ele jurou. ${ }^{\text {R.14) }}$ Diante de Abuwaqar, filho de Iddin-Irra, ${ }^{15)}$ diante de Ubar-Šamaš, filho de Ilî-išmeanni, ${ }^{16)}$ diante de Šu-nașir, filho de Šu-Dumuzi, ${ }^{17)}$ Sîn-ma-ilum, filho de Ahušunu, ${ }^{18)}$ diante de Tizqarum, filho de Ilî-iddinam, ${ }^{19)}$ diante de Šêrum-ilî, filho de Sîn-irîbam, ${ }^{20)}$ diante de Hazirum, filho de Êtamši-ilam, ${ }^{21)}$ diante de Anna-imitti. ${ }^{22)}$ Os selos das testemunhas. Mês: IX ${ }^{23-25)}$ Ano: 8 Rîm-Sîn.

Dimensões: $6,8 \times 4,2 \mathrm{~cm}$.

1.1: o termo sumério é-gal ${ }^{\text {lam }}$ corresponde ao acadiano êkkalum, que indica normalmente o palácio; no entanto, mais raramente, significa também o 'cômodo principal' de uma casa (cf. CAD, E: 60: main room of a private house, e também D. Charpin ${ }^{25}$ ). Assim, a aproximação sugerida por L. Matouš ${ }^{26}$ com uma forma abreviada de é-ki-gallam não parece se justificar.

1.7: a cópia do tablete permite resgatar o preço do terreno, que havia desaparecido do envelope copiado por Jean.

${ }^{25}$ D. Charpin, 'La politique immobilière des marchands de Larsa à la lumière des découvertes épigraphiques de 1987 et 1989', in J.-L. Huot, ed., Larsa. Travaux de 1987 et 1989, Bibliothèque Archéologique et Historique, 165, Beyrouth, Institut Français d'Archéologie du Proche-Orient, 2003, p. 311-322 (cf. p. 316).

${ }^{26}$ L. Matouš, Les contrats de vente d'immeubles provenant de Larsa. Archiv Orientální, 18, p. 11-67, 1950. (cf. P. 21). 
AO 6389 (TCL,10,37 - Tablete)

FIG. 4A

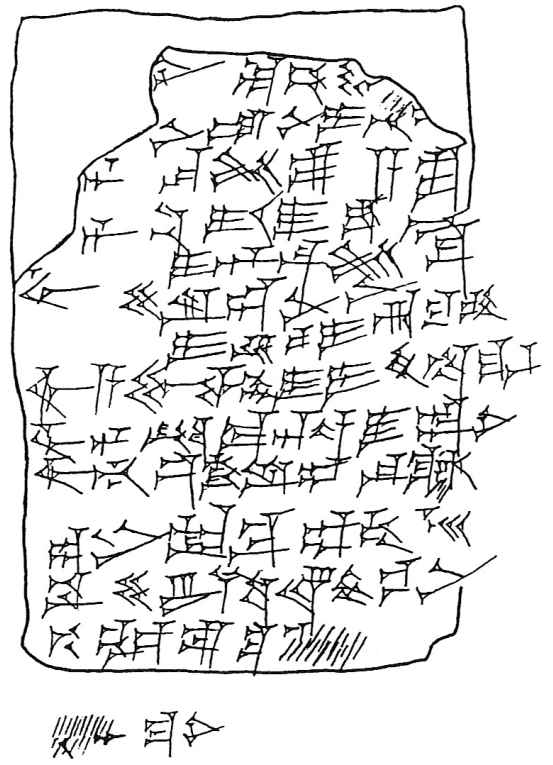

FIG. 4B

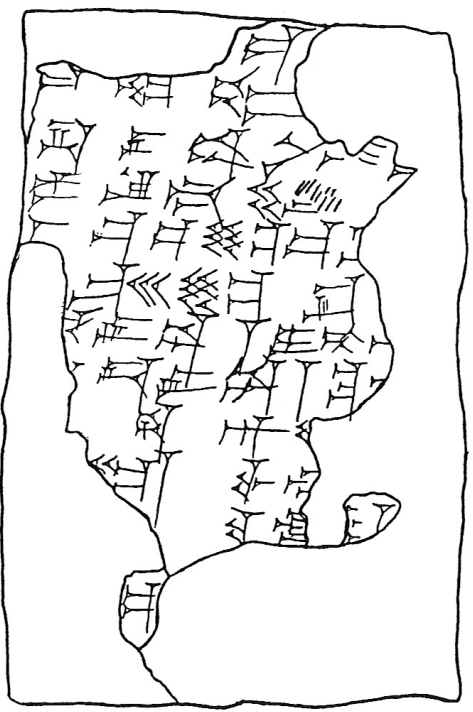




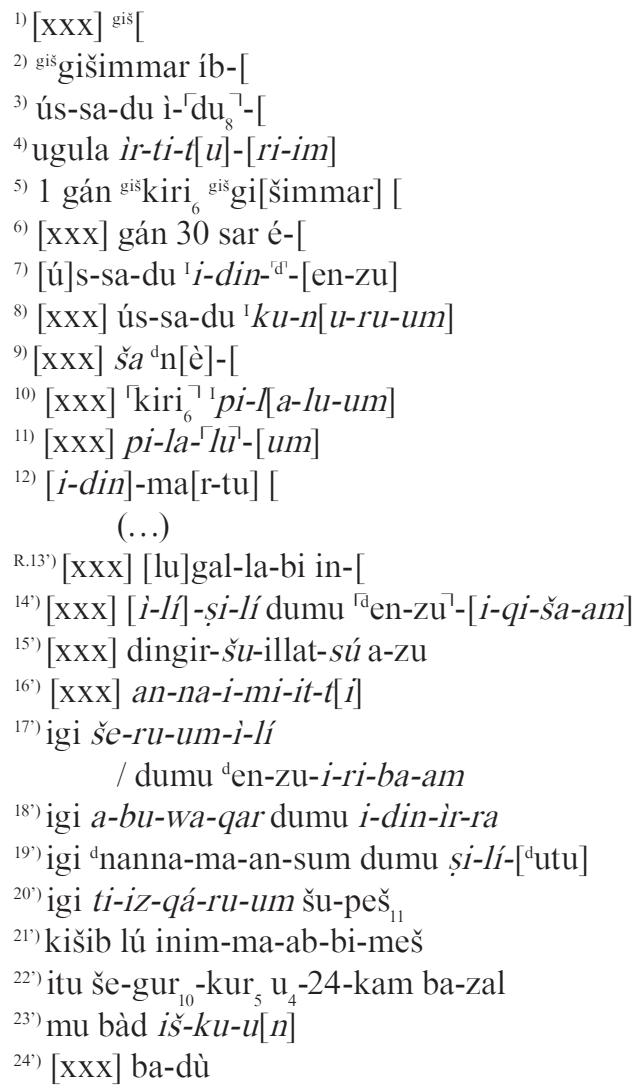

Este tablete encontra-se bastante danificado e não permite adicionar quase nada de importante ao texto do envelope, cuja tradução é dada por E. Bouzon ${ }^{27}$. Acrescentemos apenas que, na 1. 6, o significado exato do termo é-ki é difícil de estabelecer; trata-se, certamente, de um terreno rural, talvez inculto, o que o aproximaria do kislah. Em sua tradução citada acima, E. Bouzon transcreveu os sinais como gán-ki, preferindo deixá-los sem equivalente. Por outro lado, conhece-se também uma designação é-ki-gal, que D. Charpin ${ }^{28}$ traduz simplesmente por 'terrain nu'. Para a ocorrência em um texto do tipo 'ditila' (resumo de processo) da época neo-suméria (ITT, III $\left.^{2}, 6533\right)$, A. Falkenstein ${ }^{29}$ também não sugeriu um caráter específico para este terreno: '... -Grundstück', mas ver o índice (vol. 3, 111, s.v. gána-ki-a = 'unbebautes Land').

${ }^{27}$ E. Bouzon, Contratos Pré-Hammurabianos do reino de Larsa. Porto Alegre: Edipucrs, 2000.

${ }^{28}$ D. Charpin, Archives Familiales et propriété privé en Babylonie ancienne: étude des documents de Tell Sifr; Hautes Études Orientales, 12, Genève, Librairie Droz, 1980, p. 132.

${ }^{29}$ A. Falkenstein, Die neusumerischen Gerichtsurkunden, v. 2, Abhandlungen, Bayerisch 
AO 6360 (TCL,10,67 - Tablete)

FIG. 5A

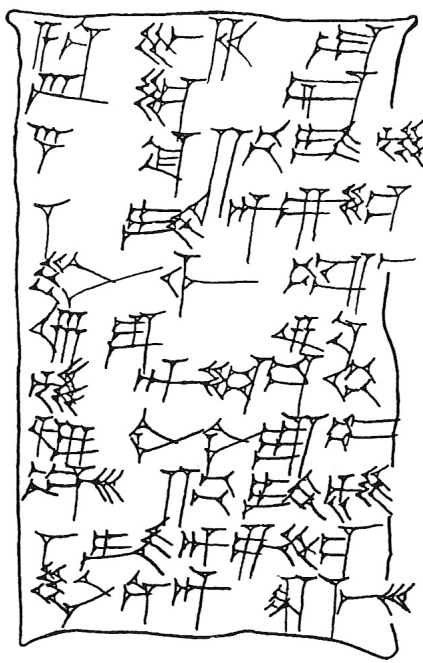

FIG. 5B

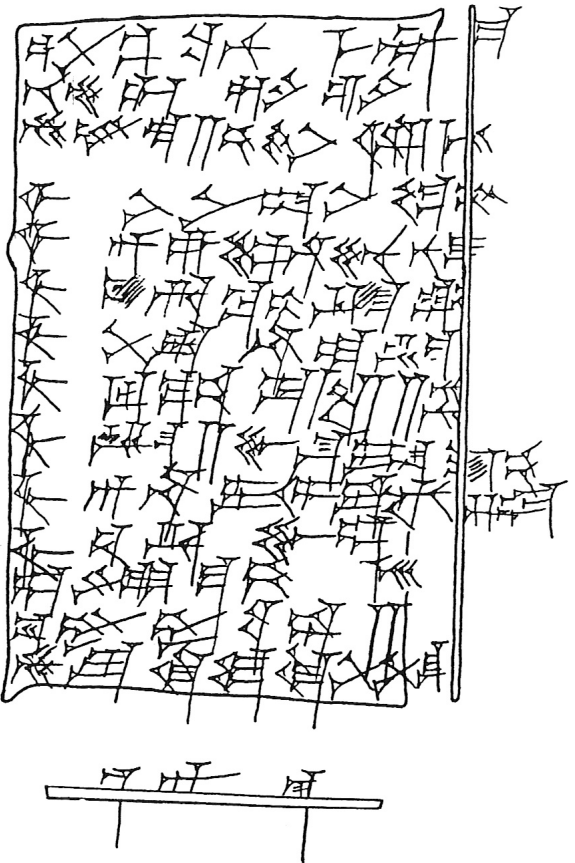




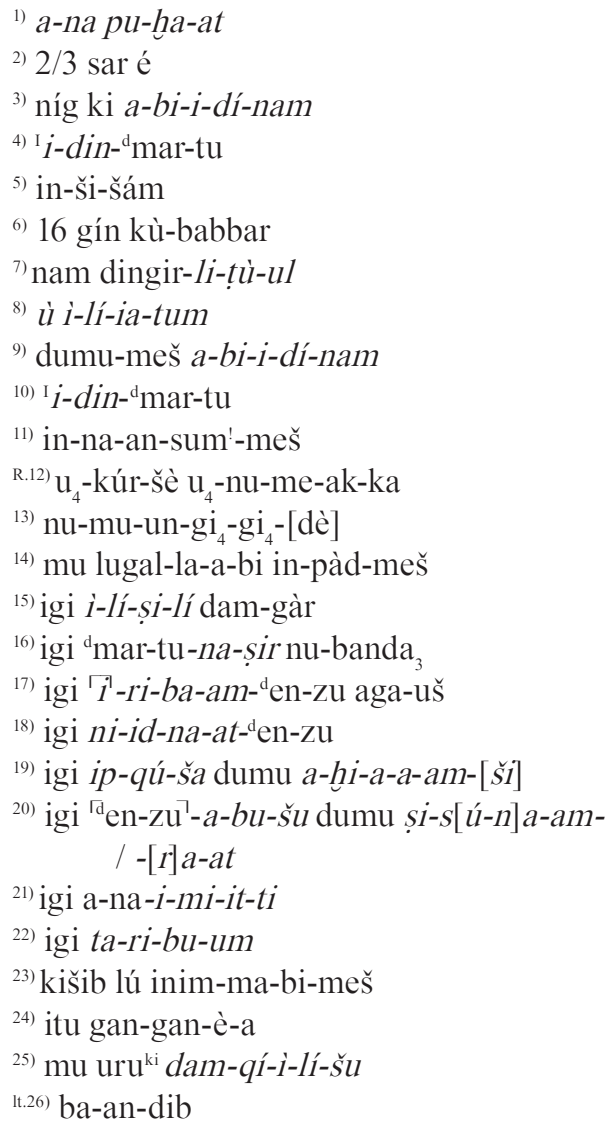

1) Em compensação ${ }^{2)}$ por $2 / 3$ de sar de casa ${ }^{4)}$ que Iddin-Amurrum ${ }^{5)}$ havia comprado ${ }^{3)}$ de Abi-iddinam, ${ }^{10)}$ Iddin-Amurrum ${ }^{\text {R.11) }}$ deu $^{6)} 16$ siclos de prata ${ }^{7)}$ a Ilî-lițtul ${ }^{8)}$ e Iliyatum, ${ }^{9)}$ os filhos de Abi-Iddinam. ${ }^{12)}$ No futuro e para sempre, ${ }^{13)}$ eles não se voltarão (contra o contrato). ${ }^{14)}$ Em nome de seu rei, eles juraram. ${ }^{15)}$ Diante de Ilî-șilli, mercador, ${ }^{16)}$ diante de Amurrum-nașir, nu-banda $\left.{ }_{3},{ }^{17}\right)$ diante de Iribam-Sîn, soldado-rêdûm, ${ }^{18)}$ diante de Nidnat-Sîn, ${ }^{19)}$ diante de Ipquša, filho de Ahiya-amši,${ }^{20)}$ diante de Sîn-abušu, filho de Șisu-namrat, ${ }^{21)}$ diante de Anna-imitti, ${ }^{22)}$ diante de Tarîbum. Os selos das testemunhas. ${ }^{23)}$ Mês: IX ${ }^{\text {R.24-25) }}$ Ano: 25 de Rîm-Sîn.

Dimensões: $6,6 \times 4,4 \mathrm{~cm}$.

1. 2: o complemento da linha, que só se encontra no envelope, deixa clara a natureza do documento, uma compensação paga em função da intervenção de uma decisão real: ša șí-im-da-at lugal = que (está sob) o decreto do rei. 
1.16: para este título, equivalente ao acadiano laputtûm, ver AHw,1: $537 \mathrm{e}$ CAD,L: 97; não é possível estabelecer a natureza exata de sua função: responsável pela administração palaciana, oficial militar ou outro.

1. 19: D. Arnaud ${ }^{30}$ leu a partir do envelope (= cópia de Jean): $a-l i-a-X-s ̌ i l . ~ O$ tablete permite alterar e completar a leitura.

\section{AO 6426 (TCL,11,194 — Fragmento de envelope)}

FIG. 6

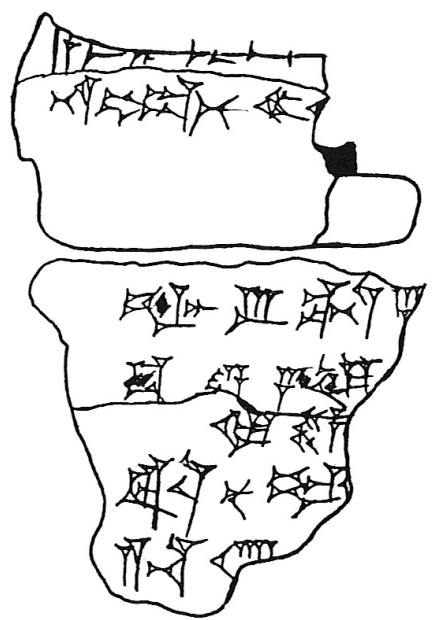

$$
\begin{aligned}
& \text { R. 1') } \Gamma_{7} s a-a m-s u \overrightarrow{-}-[ \\
& \text { It.2’ na-qá-ab nu-uh-[S }] i \\
& \text { (...) } \\
& \text { 1) šám 2/3 ma-na } 55 \text { [ } \\
& { }^{2)} \text { síg-hi-a níg-bún-[ } \\
& \text { / ù sum }{ }^{[\mathrm{sar}]} \\
& \text { 3) su-ut nu-úr-[ } \\
& \text { 4) a-na }\ulcorner 17\urcorner[
\end{aligned}
$$

O texto é muito fragmentário para servir de base para uma tradução. $\mathrm{O}$ interesse do fragmento é permitir a datação do contrato. Com o concurso do tablete (= cópia de Jean), pode-se estabelecer o seguinte texto:

Akademie der Wissenschaften, 39, München, Verlag der Bayerischen Akademie der Wissenschaften, 1956/7, p. 15.

${ }^{30}$ Ver D. ARnaud, TCL X et XI: ajouts et corrections, Revue d'Assyriologie et d'Archéologie Orientale, 70, p. 84-92, 1970. 
1) $2 / 3$ de mina e 5 siclos, (é) o valor ${ }^{2)}$ da lã, de tartarugas, de tâmaras e de cebolas, ${ }^{3)}$ lote de Nûr-Šamaš, ${ }^{4)}$ (que), por 17 1/2 siclos de prata selada, ${ }^{6}$ IbniAmurrum $^{7)}$ comprou $^{5)}$ de Nûr-Šamaš. ${ }^{\text {R.8-9) }}$ No dia em que a prata do palácio for exigida, ${ }^{11)}$ Ibni-Amurrum ${ }^{12)}$ pagará ${ }^{10)}$ a prata do palácio. ${ }^{13)}$ Diante de Amurrumtayyar, ${ }^{14)}$ Girni-isa ${ }^{15)}$ Mês: VII, $24^{\circ}$ dia ${ }^{16-18)}$ Ano: 3 de Samsu-iluna.

1.2: Nos arquivos de Ibni-Amurrum, a tartaruga (̌̌eleppûm, cf. CAD, Š: 271 s.: turtle; e AHw,2: 1210: eine Schildkröte) aparece em duas variantes em relação à grafia tradicional, níg-bún-na-ku : níg-bún-ku ${ }_{6}$ (TCL,11,194 e 195) e níg-bún-a-ku 6 (TCL,11,205). A tartaruga-šeleppûm deve ser diferenciada da tartaruga-raqqum (grafada ba-al-gi-ku ${ }_{6}$ cf. CAD,R: 172 s. AHw,2: 958); para as tartarugas, em geral, ver D.I. Owen ${ }^{31}$ e cf. tambèm W. Farber ${ }^{32}$. Para uma tentativa de correspondência com o árabe iraquiano moderno, ver A. Cavigneaux e F. Al-Rawi ${ }^{33}$. Para as tartarugas no quadro da pesca na época da terceira dinastia de Ur, ver R.K. Englund ${ }^{34}$.

1. 8-9: para esta frase, ver os comentários de F. Pomponio ${ }^{35}$.

\section{AO 6423 (TCL,11,195 — Tablete)}

Lateral superior do tablete visível por uma brecha do envelope

FIG. 7

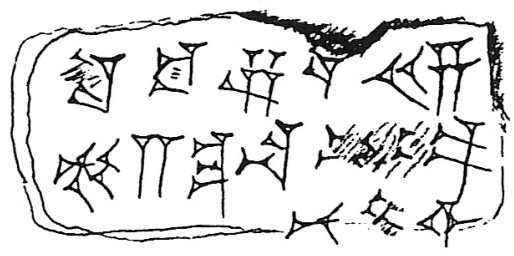

\footnotetext{
1) itu du $-\mathrm{kù} \mathrm{u}_{4}-24-[\mathrm{kam}]$

2) ${ }^{2} \mathrm{i} \mathrm{i}_{7}$ na-qá-ab

/ nu-uh-ši
} (cf. p. 40s.)

${ }^{31}$ D.I. Owen, Of birds, eggs and turtles, Festschrift für Assyriologie, 71, p. 29-47, 1981

${ }^{32}$ H. FARBer, Von BA und anderen Wassertieren - testudines sargonicae?, Journal of Cuneiform Studies, 26, p. 195-207, 1974 (cf. p. 195).

${ }^{33}$ A. Cavigneaux, e F. Al-Rawi, New Sumerian literary texts from Tell Haddad (ancient 
O envelope AO 6423 permanece fechado e foi restaurado pelo Louvre; seu estado atual não recomenda, portanto, uma abertura. Todavia, uma lateral quebrada do envelope permite ver 2 linhas de sinais do tablete interior, que contêm a fórmula de datação do contrato:

${ }^{1)}$ Mês: VII, 24 ${ }^{\circ}$ dia $^{2)}$ Ano: 3 de Samsu-iluna.

No envelope, lê-se:

1) $2 / 3$ de mina e 5 siclos de prata, (é) o valor ${ }^{2)}$ da lã, de tartarugas, ${ }^{3)}$ de tâmaras e de cebolas, ${ }^{4)}$ lote de Nûr-Šamaš. ${ }^{5)}$ Ibni-Amurrum, ${ }^{\text {) }}$ filho de Iddin-Amurrum ${ }^{8)}$ comprou ${ }^{7)}$ por $(. .$.$) de prata. { }^{\text {R.9) }}$ No dia em que o palácio exigir a prata, ${ }^{10)}$ Ibni-Amurrum ${ }^{12)}$ pagará ${ }^{11)}$ a prata do palácio. ${ }^{13)}$ Diante de Amurrum-tayyâr, ${ }^{14)}$ filho de Samum, ${ }^{15)}$ diante de Girni-isa, ${ }^{16)}$ filho de Ibni-Adad. ${ }^{17)}$ Mês: VII, $24^{\circ}$ dia ${ }^{18-19)}$ Ano: 3 de Samsu-iluna.

\section{AO 6396 (TCL,11,197)}

Lateral inferior não copiada por Ch.-F. Jean

FIG. 8

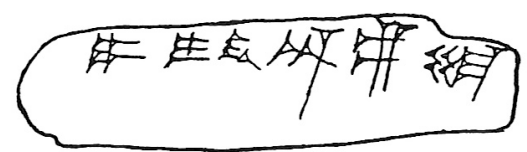

${ }^{\text {t..17) }}$ dumu i-din- ${ }^{\mathrm{d}}$ mar-tu

A cópia permite um pequeno acréscimo, explicitando a filiação de IbniAmurrum: ${ }^{\text {t.17) }}$ filho de Iddin-Amurrum.

Meturan): a first survey, Iraq, 55, p. 91-105, 1993 (cf. p. 103).

${ }^{34}$ R.K. EngLund, Organisation und Verwaltung der Ur III-Fischerei, Berliner Beiträge zum Vorderen Orient, 10, Berlin, Dietrich Reimer Verlag, 1990 (cf. p. 222).

${ }^{35}$ F. Pomponio, Tre testi antico-babilonesi editi in ITT, III, Mesopotamia, 17, p. 35-41, 1982 (cf. p. 41). 
AO 6397 (TCL,11,199)

Fragmento de envelope colado no verso do tablete

FIG. 9

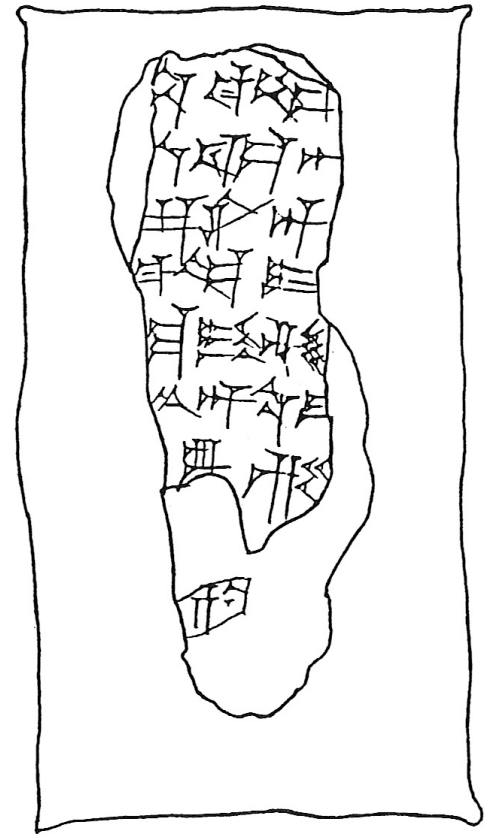

\section{(..)}

1) [i]-na itu ne-[ne-gar]

2) [kù-bab]bar ka-a[n-ka-am]

3) [1] $i b-n i-\mathrm{d}[\mathrm{mar}-\mathrm{tu}]$

4) [é-gá] $]^{\text {lam }} i-[i p-p a-a l]$

5) [igi den]-zu-i-dí-nam [

6) $\left[{ }^{1} w a-t a\right] I^{\mathrm{d}} \mathrm{dutu}$ dumu [

7) ['en-zu]-ú-sé-[II]

8) [

9) [kišib-ba]-a-[

\section{$(\ldots)$}


O envelope de AO 6397 praticamente desapareceu, certamente por obra dos escavadores ilegais ou antiquários do mercado negro que 'limparam' a peça antes de vendê-la ao Louvre. No entanto, uma parte permaneceu colada ao tablete. Assim, o fragmento de envelope permite completar parcialmente a passagem do texto do tablete interno que ele oculta debaixo de si. No conjunto, pode-se ler, então:

1) $32 / 3$ minas e 3 siclos de prata, (é) o valor ${ }^{2}$ de peixes do mar, de tâmaras e de cebolas ${ }^{3)}$ da corporação de mercadores de Lagaš. ${ }^{4)}$ Por 1 mina e 5 5/6 siclos de prata, ${ }^{5)}$ a ser fornecida ao palácio, ${ }^{17}$ Ibni-Amurrum ${ }^{18)}$ comprou-os ${ }^{6}$ de Mâr-erșetim, () Sîn-uselli, ${ }^{8)}$ Sîn-kašid, 9) Sîn-pilah, ${ }^{10)}$ Kunnî, ${ }^{11)}$ Bêlî-ašarid, 12) Šamaš-magir, ${ }^{13)}$ Ibbi-Šamaš, filho de Ilî-mahi, ${ }^{14)}$ Ilî-ippašram, filho de ȘilliŠamaš, ${ }^{15)}$ Awîl-ilî, filho de Ilî-unnenî, ${ }^{16)}$ e Ibbi-Ninšubur, chefe de um grupo de

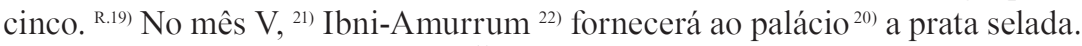
${ }^{23}$ Diante de Sîn-iddinam, ${ }^{24}$ Watar-Šamaš, filho de Sîn-imguranni, ${ }^{25)}$ Sîn-uselli, filho de (...)-Šamaš, ${ }^{26)}$ Șilli-Šamaš, escriba. ${ }^{27)}$ Seus selos foram impressos. ${ }^{28)}$ Mês: VI, no decorrer do (...) dia ${ }^{29-32)}$ Ano: 3 de Samsu-iluna.

\section{Abreviaturas}

AbB Altbabylonische Briefe (Leiden).

AHw W. Von SODEN - Akkadisches Handwörterbuch. 3 volumes. Wiesbaden, 1965-1981.

AO Antiquités Orientales (inventário dos tabletes do Museu do Louvre).

CAD The Assyrian Dictionary of the Oriental Institute of the University of Chicago.

1.: linha

1t.: lateral do tablete.

$\mathrm{R}$ : verso do tablete.

TCL Textes Cunéiformes du Louvre (Paris).

TLB Tabulae Cuneiformes a F. M. Th. de Liagre Böhl Collectae (Leiden).

VS Vorderasiatische Schriftdenkmäler (Berlin).

YOS Yale Oriental Series (New Haven).

\footnotetext{
"Nota do Editor. Texto formatado com a fonte especializada Xerxes, fornecida pelo autor.
} 
Agradecimentos. Gostaria de expressar meu mais elevado agradecimento a Béatrice André-Salvini, Conservadora-Chefe dos tabletes cuneiformes do Museu do Louvre por me ter confiado a publicação destes documentos inéditos do reino de Larsa. As sessões de trabalho nas reservas do Museu prolongaram-se entre 1999 e 2002, no quadro de um estágio de formação em epigrafia cuneiforme. As cópias e traduções aqui apresentadas contaram com a inestimável supervisão do Prof. Dominique Charpin e foram apresentadas em minha tese de Doutorado, defendida sob sua direção na Sorbonne, em junho de 2004. Na ocasião, algumas sugestões de releitura foram feitas pelo Prof. J.-M. Durand, do Collège de France, permitindo uma compreensão mais adequada de certas passagens. O início de meu trabalho com os arquivos da família Sanum foi possível graças aos estímulos do Prof. E. Bouzon (PUC-RJ) que não hesitou em me antecipar o resultado de suas próprias traduções, então inéditas. O Prof. Bouzon dignou-se igualmente a ler os originais deste trabalho. A todos devo um amplo reconhecimento.

RÉsumé. Documents cunéiformes inédits du Musée du Louvre : les archives de la famille Sanum. Une des taches les plus importantes de l'épigraphie cunéiforme est de rendre disponibles plusieurs milliers de documents qui demeurent inédits dans les résèrves des musées. En ce qui concerne l'histoire économique, une étape incontournable est de rassembler et publier les archives familiales mésopotamiennes qui ont été la source d'un considérable renouvellement des études assyriologiques pendant les dernières décennies. Dans cet article, on présente les copies, les traductions et les commentaires philologiques de quelques tablettes inédites du Musée du Louvre, ce qui permet de compléter les archives connues de l'importante famille Sanum, de Larsa, vivant pendant la période babylonienne ancienne.

Mots-Clés. Larsa; Mésopotamie; archives familiales; Sanum; écriture cunéiforme; Musée du Louvre. 